\title{
El cuerpo al servicio de la ideología: la educación física y deportiva en los fascismos europeos
}

\author{
The Body at the Service of Ideology: Physical and \\ Sports Education in European Fascisms
}

\author{
Marta Mauri Medrano*
}

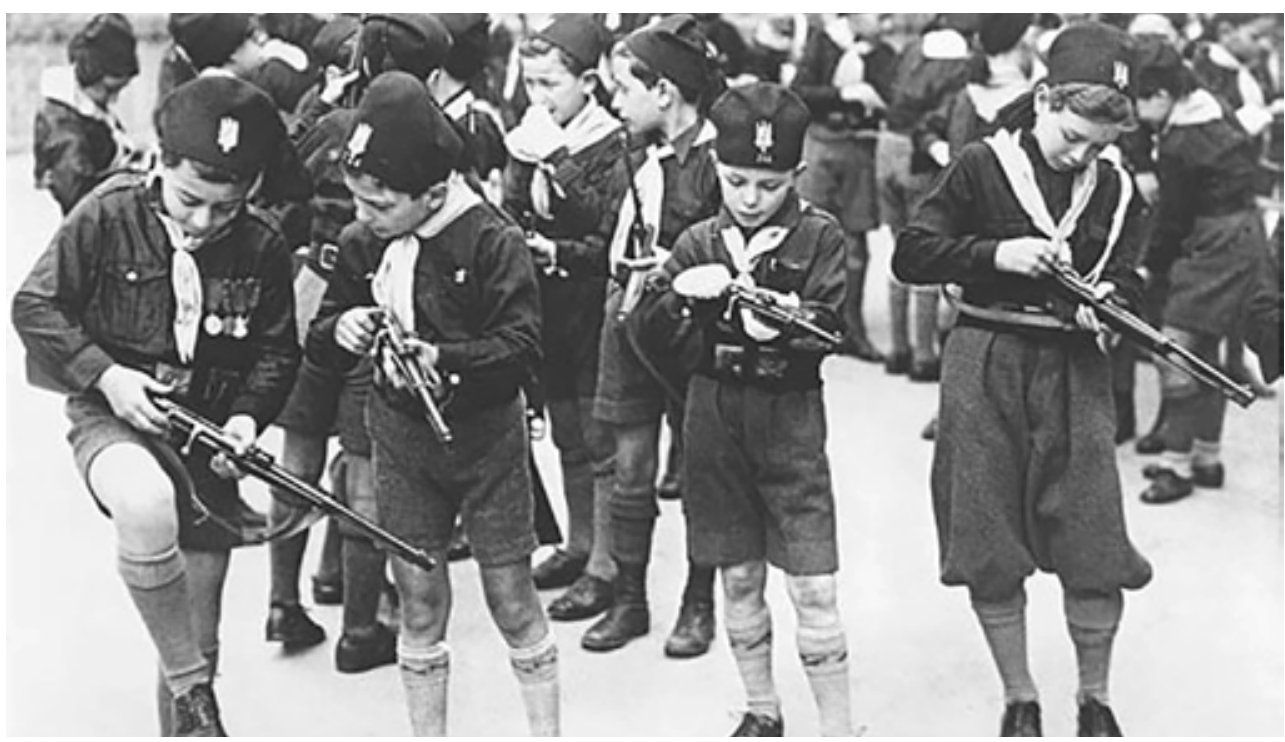

\section{Resumen}

Este artículo tiene la intención de analizar cómo las organizaciones fascistas juveniles utilizaron el cuerpo del joven como símbolo político. A través del adoctrinamiento, las Juventudes Hitlerianas, la Opera Nazionale Balilla y el Frente de Juventudes lograron conseguir una base social de jóvenes que utilizaron como símbolo de lealtad al proyecto político fascista. Este texto también pretende abrir nuevas vías interpretativas en la temática del cuerpo, estableciéndolo como un objeto legítimo de investigación histórica.

Palabras clave: fascismo, organizaciones juveniles, educación física.

Citar este artículo como: Mauri Medrano, M. (2019). El cuerpo al servicio de la ideología: la educación física y deportiva en los fascismos europeos. Revista Papeles, 11(21), 78-87.

Fecha de recibido: marzo 15 de 2019 • Fecha de aceptación: mayo 30 de 2019

* Dra. en Ciencias de la Educación, con una especialidad en Teoría e Historia de la Educación Física. Profesora en la Universidad Zaragoza. Correo electrónico: mmauri@unizar.es 


\begin{abstract}
This article aims to analyze how the fascist youth organizations used the youth body as a political symbol. Through the indoctrination of Hitler Jugend, the Opera Nazionale Balilla and Frente de Juventudes managed to get a social base of young people used as a symbol of loyalty to fascist political project. This text also aims to open new interpretive paths in the body's themes - establishing it as a legitimate object of historical research.
\end{abstract}

Key Words: fascism, organizations, physical activity.

\title{
Introducción
}

Las múltiples influencias recibidas por la obra de Norbert Elias El proceso de civilización (Elias, 1987) tuvieron un papel esencial en la construcción del cuerpo como objeto de investigación dentro de las disciplinas sociales. Asimismo, los trabajos de Foucault (Foucault, 1978) y De Certeau (De Certeau, 1985) también ayudaron a renovar las investigaciones sociales sobre la condición corporal. Como ya señaló uno de los grandes especialistas en la historia del cuerpo, Jean-Jacques Courtine (Courtine 2005, p. 22), el descubrimiento del cuerpo como objeto de reflexión teórica surgió del campo de la antropología, sobre todo de las ideas de Marcel Mauss (1934) y de su ya famosa obra sobre las "técnicas corporales" que aparecieron en su ensayo de 1934.

No podemos repensar la idea del cuerpo y actividades físicas durante los fascismos sin acudir a la condición de juventud, cuya significación parece fácilmente tributaria de la edad y profundamente conectada con el cuerpo. Los fascismos exhibieron el cuerpo del joven como símbolo político por antonomasia; no consistía tan solo en adoctrinar y politizar a la infancia y la juventud para que se convirtieran en la base productiva del futuro fascista, también radicaba en mostrar a los jóvenes y a sus cuerpos como símbolos políticos leales al Estado, una juventud que se renovaría generación tras generación, convirtiendo al fascismo en "eternamente joven".

En el presente artículo se abordará cómo el cuerpo y las prácticas físicas, asociados siempre a la condición de juventud, fueron utilizados meticulosamente por los fascismos europeos, tanto por la Alemania nazi con las Juventudes Hitlerianas, la Opera Nazionale Balilla en la Italia de Mussolini y en el Frente de Juventudes durante el franquismo. El cuerpo fue profundamente instrumentalizado al servicio de la causa ideológica fascista, convirtiéndolo en el blanco de discursos, saberes y prácticas que lo utilizaron como signo político propagandístico y publicitario.

\section{El fascismo italiano y la Opera Nazionale Balilla}

El joven, el cuerpo juvenil robusto, uniformado, altivo, funcionaba como eficaz dispositivo simbólico, donde tomaba un valor universal y absoluto. Más allá de los límites históricos y cronológicos, el cuerpo juvenil ha sido exhibido en la mayoría de corrientes y movimientos políticos como fuente de progreso, de fuerza, de vida. Así se afirmaba también en la prensa de la Italia fascista de Mussolini: "nuestra juventud es el símbolo que domina, desvinculado del espacio y del 
tiempo: en él se resume el amor y la belleza, la fuerza y el canto"1.

La juventud y su eternidad servían para mostrar una nación perpetuamente joven, donde los cuerpos juveniles suponían un símbolo de esa "estirpe" tan valiosa para el fascismo, que se manifestaba en la elección política de un régimen que había hecho de los jóvenes el punto de apoyo de su acción y el centro de su sistema organizativo (Malvano, 1996, p. 314). La juventud se convertía, así, en un elemento constitutivo del fascismo, adquiriendo una dimensión totalmente simbólica:

el Fascismo es juventud, pero la inexorable ley del tiempo es envejecimiento y ¿qué será del fascismo a medida que vaya envejeciendo? (...) El envejecimiento de los hombres es un hecho, pero la Estirpe, si no está condenada a la extinción por culpa de una tara degenerativa, se renueva perpetuamente. El Fascismo, que ha surgido de las más vivas energías de nuestra Estirpe... para no llegar a envejecer y a degenerar a su vez, debe perder los elementos de debilidad y caducidad que son innatos a todos los "partidos", y seguir con la naturaleza igualándose con la Estirpe, y consiguiendo cada año más vigor de las generaciones venideras ${ }^{2}$.

Fue, eminentemente, la imagen del efebo atlético y fuerte, joven vigoroso y sano, a quien le correspondía representar el propio fascismo. El joven y su cuerpo se convertían en símbolo material, político, social, económico y cultural, al cual se le encomendaba una ardua tarea: la de simbolizar, representar y legitimar al fascismo, por lo que el joven debía reproducir y manifestar todo de lo que él se esperaba, convirtiéndose así en verdadero vehículo de transmisión ideológica.

1 "La giovinezza è un símbolo", Gioventù Fascista, 10 de febrero de 1932, 4.

2 MORGAGNI, "La leva fascista certeza del futuro", Rivista Ilustrata del Popolo d' Italia , abril de 1927, 5.
En cuanto a la educación física, la Opera Nazionale Balilla (ONB) asumía sus competencias fundamentales, tanto en el terreno escolar como extraescolar los dos objetivos principales que se propusieron fueron: por un lado, la construcción de un gran número de gimnasios y campos deportivos y, por otro, mejorar la preparación de los profesores de educación física. Para ello se creó la Academia de Roma para la formación del profesorado masculino y la Academia Fascista de Orvieto destinada a la formación de las futuras instructoras de la materia.

Como afirmaba la prensa de la época, "del fascismo fuerza viva es la práctica deportiva" El deporte se ritualizó y se convirtió en un estilo de vida, el deporte no solo era una mera competición sino que también suponía una educación indispensable para la masa, para el colectivo, donde el joven se sentía parte del proyecto político que estaba simbolizando (Martin, 2004, p. 31). El joven era el protagonista de la práctica deportiva, donde desfilaba, marchaba con la cabeza erguida, haciendo uso de una retórica corporal del honor tan vistosa en los fascismos:

el paso de los jóvenes debe ser tan ágil y veloz que expresa la energía, el atletismo y la perfecta forma física (...) En la carrera no existen solo velocidad y desarrollo de la armonía, también está representado el símbolo de la acción rápida y del movimiento constante del fascismo ${ }^{4}$.

Esta imagen del deporte y del joven atlético ayudó a configurar la nueva identidad del ciudadano italiano, dinámico y musculoso, que soportaba sobre su cuerpo la importancia de asegurar un beneficio físico y político para la nación. El deporte no era algo superficial, detrás de él se configuraban principios como la lucha, el espíritu competitivo, la combatividad $\mathrm{y}$ otros pilares fundamentales del fascismo. El

3 Il Balilla, 28 de febrero de 1929.

4 "Sfilare di corsa", Gioventù Fascista, 10 de febrero de 1933. 


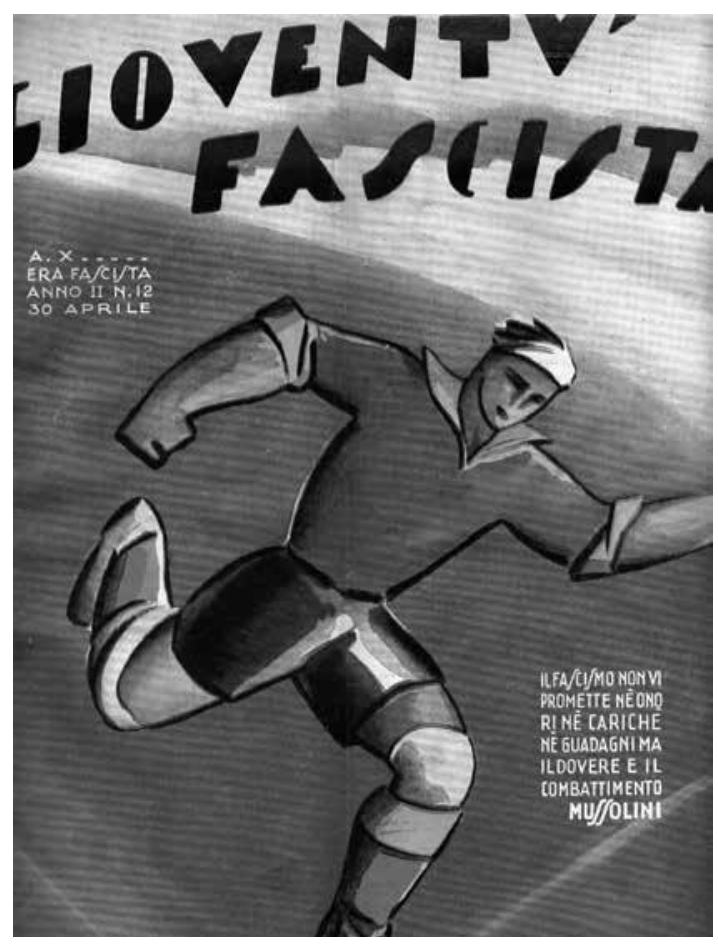

Número de la revista de Gioventù Fascista, revista para los jóvenes italianos

fútbol o el ciclismo, al igual que otros deportes, llegaron a convertirse en deportes de masas y supusieron potentes vehículos de identidad nacional donde se mostraban las glorias y victorias deportivas.

A través de las imágenes de la prensa juvenil se aleccionó a la infancia y la juventud italiana de los años treinta en un concreto modelo deportivo, con una clara función didáctica, ya que constituía un medio de trasmisión privilegiado de los valores más apreciados por el fascismo: la exaltación de la preparación física y de la autodisciplina, el valor del espíritu combativo y la importancia de las relaciones de equipo (Malvano, 1996, p. 324). Así lo mostraban las portadas de la revista dirigida por Starace, Gioventù Fascista, que presentaban numerosas imágenes de jóvenes atletas políticamente comprometidos con el régimen, y con claras alusiones a frases del Duce, al igual que hizo el Frente de Juventudes en muchas de sus publicaciones. Era la idea de "una juventud fuerte física y espiritualmente" ${ }^{5}$ que constituía uno de los pilares ideológicos del fascismo y que además se convertía en una poderosa metáfora visual que permitía trasmitir mensajes de contenido mucho más complicado de lo que a simple vista podían parecer.

El deporte era el elemento que permitía la regeneración de la raza, con la eliminación de los débiles y el triunfo de los fuertes y sanos, quienes dominarían el mundo y legitimarían el sistema político fascista. La cuestión deportiva tenía la clara ventaja de ser el portador de un mensaje directo, del que se obtenía un provecho inmediato y que se adaptaba fácilmente a cualquier destinatario: "la rapidez, la eficacia y la preparación física, que estaban en la base del mito deportivo, podían convertirse en eficaces transmisores del 'joven Estado fascista, dinámico y moderno" (Malvano, 1996, p. 326).

\section{"Nuestro cuerpo no nos pertenece, es de la nación": las Juventudes Hitlerianas en la Alemania Nazi}

Las Hitler Jugend o Juventudes Hitlerianas fueron instituidas en 1922. Tras el ascenso de Hitler al poder en 1933 estas organizaciones tomaron tal importancia que en 1936 ya contaban con más de cinco millones de afiliados. El servicio activo pasó de ser de carácter voluntario a obligatorio: todos los niños y niñas debían servir en esta organización de manera forzosa, al igual que ocurría en el Frente de Juventudes durante la etapa franquista o en la Italia de Mussolini con los niños entre ocho y dieciocho años. ${ }^{5}$

5 Metodo per l'educazione física dei balilla, Opera Nazionale Balilla, Tipografía Moyne y Alessandroni, Roma, 1932, 7. 
La escuela fascista asumía la ardua tarea de la formación de los jóvenes, unos jóvenes que se convirtieron en el símbolo de la pureza de la Alemania nazi. Unos jóvenes que a su vez eran el blanco de las prácticas militaristas del III Reich, que los consideraba esenciales para poder sustentar el proyecto expansionista de Hitler. Estos jóvenes se convertían en "pequeños soldaditos" desde muy temprana edad, como ya señaló Alfred Baümler, catedrático en la Universidad de Berlín, en una conferencia en 12 de junio de 1933, aludiendo que en las prácticas educativas debía premiar la "educación soldadesca del joven” (Michaud, 1996, p. 351).

Al igual que ocurría en el caso del Frente de Juventudes o la ONB, al aprendizaje escolar de marcado carácter fascista se le añadía el aprendizaje de la competencia dentro de la organización, ejercida por sus superiores con actividades deportivas y de carácter competitivo. El cuerpo era sustancial para estas competiciones, solo los mejores lograrían unos óptimos resultados, llegando a convertirse en los líderes del mañana. Según sus dirigentes, las Juventudes Hitlerianas tenían que ser las "escuelas de la nación" ya que tenían la misión, al igual que en el Frente de Juventudes, de suplantar a la familia y a la escuela en algunas tareas educativas, como así afirmaba Hitler en su discurso hacia las Hitler Jugend en septiembre de 1935 en Núremberg:

Hemos emprendido el educar de este pueblo de una manera nueva, de brindarle una educación que se inicia en la juventud, para no acabar nunca. En el futuro, el joven pasara de una escuela a otra. Eso comenzará con el niño, y acabará con el viejo combatiente del movimiento. Es preciso que nadie pueda decir que habrá para él un tiempo en que se le deje a su albedrío (Michaud, 1996, p. 351).

El muchacho tenía ante todo que endurecer su cuerpo: "tu cuerpo no te pertenece, es de la nación" se leía en muchos de los carteles publicitarios y de propaganda de las Hitler Jugend. Los ejercicios físicos, que se habían duplicado en tiempo y dureza en los nuevos programas escolares, se encaminaban a la resistencia y a la competición. A los diez años el niño debía recorrer diariamente entre ocho y diez kilómetros a pie, a los trece años, dieciocho kilómetros, siendo las marchas uno de los ejercicios fundamentales de los jóvenes hitlerianos.

La preocupación de los fascismos por controlar, ejercitar y politizar los cuerpos juveniles tenía un claro objetivo: convertir al cuerpo en productivo, formando así ciudadanos útiles y "sanos" capaces de luchar por su patria por encima de todo.

El deporte se había convertido en una actividad recreativa atractiva con un enorme poder tanto para los adolescentes masculinos y femeninos desde 1920. Pero el objetivo de la educación deportiva de las Hitler Jugend era también el de formar jóvenes físicamente "sanos". Las Hitler Jugend habían recibido la misión de organizar la selección de los mejores mediante unas competiciones destinadas a estimular la superación de marcas deportivas y de disciplina ideológica. Para ello, en el año 1934 se crearon las Leistungsabzeichen, las "insignias de rendimiento", que tenían como fin primordial potenciar la competitividad entre los más jóvenes; la idea de la superación invadía todas los discursos de las Hitler Jugend:

ese incesante combate por la Leistung introducía un elemento de inquietud y de actividad artificialmente forzada en la vida de los grupos (...) Los mandos de una juventud así adiestrada para la acción y la Leistung perfilaban poco a poco un estilo muy singular de dirigente, que corría de una acción a otra y hacía correr a su séquito de una acción a otra (Schoenbaum, 1967).

Esa dinámica competitiva se extendía por todas las ramificaciones de las Hitler Jugend con la institución de concursos, de campeonatos, de 
competiciones, etc. Pero como estos jóvenes condecorados pasaban a ser "soldados del trabajo" cuando cumplían los dieciocho años, el cuerpo importaba al Reich - y mucho-, pero lo hacía como fuente productiva, para luchar como militar o soldado raso, o como ciudadano útil que seguía luchando por sostener los cimientos de la Alemania nazi. Era el poder de formar parte de lo colectivo, del equipo, con el camarada, todo adornado con la teatralización y la parafernalia fascista era la seducción del espectáculo político, de la canción, del uniforme, del grupo.

Así lo afirmaba también una de las jóvenes encuadradas en las Juventudes Hitlerianas:

nos sedujo otra cosa, revestida para nosotros de un misterioso poder: la juventud desfilando prietas las filas, con las banderas al aire, al redoble del tambor y entonando cánticos. ¿No tenía esa comunidad un algo de invencible? No fue nada raro el que Hans, Sophie y todos nosotros nos afiliásemos bien pronto a las Juventudes Hitlerianas (Michaud, 1006, p. 369).

El objetivo de toda esa parafernalia era la de despertar en la juventud el deseo de participar en ella como si fuera una obra colectiva y grandiosa, al igual que ocurría en las fiestas del Frente de Juventudes, con sus canciones, sus marchas, su uniforme, sus prácticas físicas.

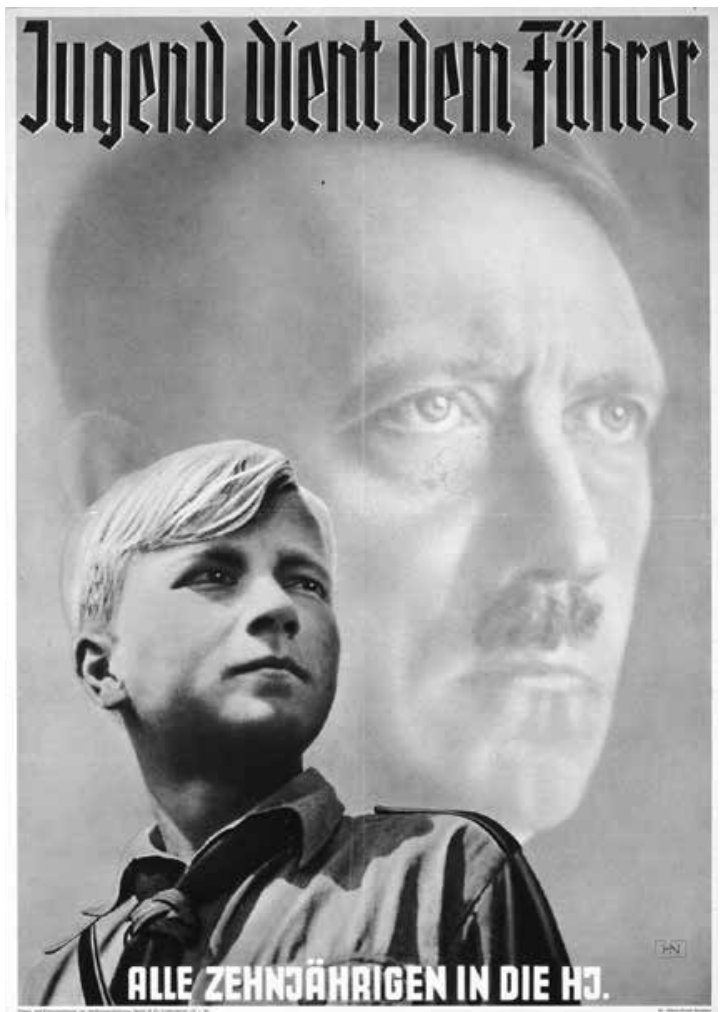

Cartel de propaganda de 1936, "La juventud sirve al Führer. Todos los muchachos de diez años a las Juventudes Hitlerianas". Coblenza, Bundesarchiv.

Toda esa espectacularidad impresionaba a la infancia, producía fervor colectivo y hacía más fácil el adoctrinamiento, ya que se jugaba con emociones públicas, con sentimientos políticos que despertaban el deseo de participación.

\section{El Frente de Juventudes durante el franquismo: "Un cuerpo fuerte para asegurar la esencia española"}

Como se ha señalado, el cuerpo se ha visto siempre atravesado por sistemas de regulaciones, a través de saberes y dispositivos, y se ha visto siempre imbuido en un campo político. Es innegable que este campo político se incrementó en los fascismos, que instrumentalizaron completamente el cuerpo de los jóvenes para ponerlo al servicio de la ideología.
En el caso del franquismo, el Frente de Juventudes ${ }^{6}$ - emulando a las Hitler Jugend o a la Opera Nazionale Balilla- controló a

6 Ley del 6 de Diciembre de 1940 instituyendo el Frente de Juventudes, BOE 7 de diciembre de 1940. El Frente de Juventudes tuvo una vida institucional de 1940 a 1960, cuando pasó a convertirse en la OJE (Organización Juvenil Española) 
los jóvenes encuadrados forzosamente en la organización juvenil a través de sus cuerpos; el cuerpo se convertía en un aptitud, en una capacidad, por la que el joven debía mostrar su lealtad al Estado.

El Frente de Juventudes ${ }^{7}$ puso el cuerpo del joven en un lugar protagónico dentro de su práctica pedagógica, y con el deporte - como agente de propaganda fascista- y la educación física - como agente disciplinador- se fue creando una serie de rituales escolares y extraescolares que impregnaron la vida cotidiana de la infancia durante los años de la dictadura franquista. Incluso la propia Ley de enseñanza primaria de 1945 ya indicaba en su título primero que la existencia de la educación física en la enseñanza primaria es una necesidad, pero no solo "en lo que atañe al cultivo de las prácticas higiénicas, sino en lo que esta educación representa fisiológicamente para formar una juventud fuerte, sana y disciplinada"s.

Esta idea del cuerpo sano e higiénico ya provenía del modelo histórico biológico del cuerpo humano. Según este paradigma, el cuerpo sano es aquel esbelto, fuerte, con destrezas y aptitudes, convirtiéndose en un cuerpo adiestrado e instrumental; una racionalización de cuerpo sometido a cánones prefijados socialmente (Scharagrosky, 1998, p. 5). Una de las consecuencias que trajo consigo este modelo,

7 Todos los escolares debían formar parte, obligatoriamente, del Frente de Juventudes y debían realizar todas las actividades que puso en marcha esta organización juvenil en la escuela. Pero no debemos confundir a los encuadrados obligatoriamente con los afiliados, ya que estos últimos eran los jóvenes que pagaban cuota y que formaron las llamadas Falanges Juveniles de Franco; su labor no se relegaba solo a la escuela sino también a otros espacios fuera del escolar. Serían los miembros de las FFJJFF los que se organizaron en varias secciones: Flechas, Cadetes y Guías y los que realizaron actividades con el objetivo de convertirse en futuros falangistas.

8 Ley de 17 de julio de 1945 sobre Educación Primaria, BOE 18 de julio de 1945. así como la introducción de la educación física y del cuerpo en la pedagogía moderna, fue la creación del "elitismo motriz", dejando de lado a los que no eran considerados "buenos", "sanos" o "adecuados" por el régimen político.

Un cuerpo sano, como explica Scharagrosky, "justificado a partir de un modelo médico hegemónico" (Scharagrosky, 1998) que coincide con los supuestos ideológicos del régimen. Un cuerpo fuerte para defender a la patria, un cuerpo fuerte para, según la ley, "asegurar la esencia española". Es a partir de las leyes y los saberes que se van construyendo en torno a la educación física - pero también sobre la educación política mediatizada a través de FEN (Formación del Espíritu Nacional) - , donde se configura la idea de un cuerpo fuerte y sano al servicio de la patria y de la nación.

El perfeccionamiento de la raza, sustentado sobre saberes pseudocientíficos y eugenésicos, dieron pie a la exaltación de lo español y su esencia y al rechazo a quienes se opusieran o no se amoldaran a sus cánones raciales y estéticos, constituyendo lo que Heller y Feher (1995) denominaron "el mito de la raza", como "mito intolerante y excluyente de un grupo particular que no soporta la existencia de ningún otro y bajo cuyo paraguas no puede sobrevivir el individuo libre".

La excusa de la salud y de la higiene vino a asegurar un normal funcionamiento del organismo y un correcto desarrollo del cuerpo, mientras que la moral haría lo suyo con el espíritu falangista para encauzar las conductas. Era una observación del cuerpo a partir de fines sanitarios, bajo la excusa del correcto crecimiento biológico de los jóvenes, y bajo la premisa de que el cuerpo debía cuidarse meticulosamente para convertirse en un instrumento del Estado en el mañana.

La moralización y medicalización del cuerpo era, efectivamente, ideológica: el cuidado del cuerpo y sus beneficios remitían a una especie de benevolencia universal de la que nadie podría negarse. La salud y control a través 
del cuerpo era vinculada al bien, al desarrollo de la raza, a la virilidad y la fuerza, mientras que el deterioro físico, el no tener un cuerpo vigoroso y hercúleo era asociado al mal. Esta dicotomía bien-mal será usada hasta la saciedad por el Frente de Juventudes como modo de adoctrinamiento físico.

El discurso de la medicalización en la enseñanza de la educación física escolar -controlada por ley por el Frente de Juventudes - fue aprovechado para penetrar en los cuerpos de los jóvenes, bajo las dicotomías normal-anormal, fuerte-débil, bueno-malo. De esta manera, la educación física contribuía a la mejora de todo el organismo para formar un cuerpo fuerte, sano, militarizado y moralmente falangista:

La vida física organizada del escolar le evita la intoxicación, favoreciendo al mismo tiempo la circulación, descongestionando los centros nerviosos y ayudando al crecimiento y desarrollo total del individuo. Respecto a la intervención de lo físico en lo moral, es algo semejante por sostener al individuo en el medio higiénico favorable, por exigirle una adaptación continua a las nuevas condiciones y por obligarle con la ejecución del movimiento a adquirir hábitos sanos que se traducen en la creación de cualidades morales (disciplina, nobleza de sentimientos, costumbres saludables, etc. [Cartilla escolar de Educación Física, 30]).

El cuerpo se convertía, así, en un texto donde se escribía la realidad social. De esta manera, la relación entre ejercicio físico y salud imponía un estilo de vida que marcaba cómo los jóvenes debían moverse, cómo vestir, cómo respirar, cómo descansar, cómo trabajar, etc. Se pretendía la homogeneización de los gestos y de los gustos, haciéndolos coincidir con las exigencias de la sociedad del momento y se impuso un estilo de vida normalizado, una salud planteada por los demás. Así se explica en la Cartilla escolar de Educación Física: comprende entre los ideales de Educación Física: un ideal vitalista o biologista respecto a asegurar la salud del niño y favorecer su crecimiento y desarrollo. Un ideal práctico referente a mejorar sus condiciones, cualidades y actividades físicas, haciéndole apto físicamente para todas las cosas. Y un ideal social y político en cuanto a formarles en un estilo y con unos fines, para que llegue a ser buen productor o soldado. Hoy día es necesario para vosotros el vigor, la fuerza, el valor y el endurecimiento y la aptitud para la lucha. Todo ello se consigue en las prácticas físicas (Cartilla escolar de Educación Física, 21).

El Frente de Juventudes practicó una pedagogía corporal acorde con sus principios políticos, hacia la formación de un cuerpo biológicamente fuerte, al servicio del Estado, disciplinado y sexualmente discriminado. Las estrategias de persuasión utilizadas por los nazis y los otros fascismos europeos tenían la intención de dar forma a nuevos sujetos políticos, para ello utilizaron el cuerpo como un medio para llegar a la mente, como vehículo adoctrinador y politizador para conseguir una base social de ciudadanos instruidos, útiles, productivos y profundamente fascistas.

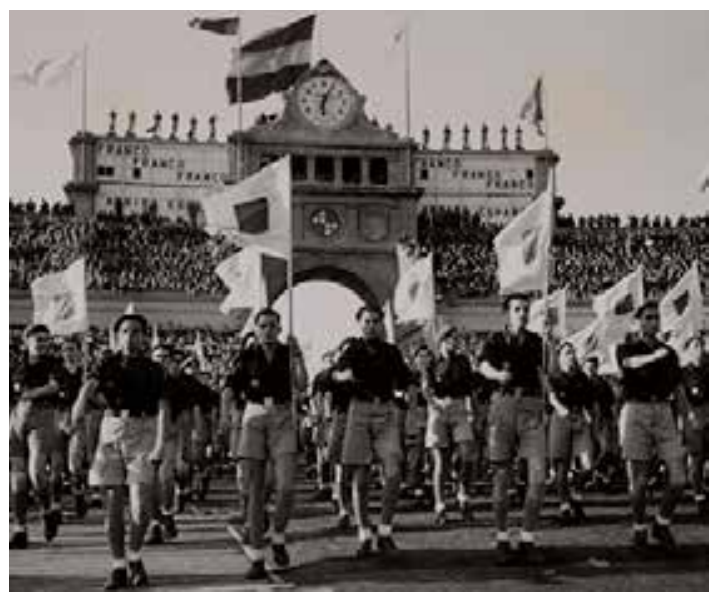

Jóvenes del Frente de Juventudes desfilando uniformados por Montjuic, 16 de abril de 1943, Archivo Provincial de Barcelona. 


\section{Consideraciones}

Como ya apuntó Vigarello (2005), el cuerpo y su estudio son un laboratorio privilegiado para las ciencias humanas, de ahí que el estudio de la historia del cuerpo radique en:

tratar de historiar lo que no parece tener historia, o lo que no parece digno de tener historia. Por eso es importante hacer visible lo que a menudo es invisible para los observadores y lo es casi siempre para nosotros (Roche, 1996).

Durante los fascismos, el cuerpo tomó un papel protagónico, siendo el blanco de distintos saberes y prácticas, que buscaban formar a los jóvenes en las técnicas militares, docilizar sus cuerpos y aprovecharse de las posibilidades que le ofrecía la imagen de una juventud eterna como fuente de legitimidad política. Los dos discursos, tanto el del militarismo - que adquirió verdadera fuerza en la ONB con el uso de armas reales- como el de la salud médica - con el racismo de por medio en el caso de las Hitler Jugend-, sustentaron y legitimaron toda la practica pedagógica y adoctrinadora de las organizaciones fascistas juveniles en el aspecto moral y corporal.

En las tres organizaciones, las actividades y prácticas físicas funcionaron de un modo muy similar, aprovechándose de la educación física y deportiva como vehículo para controlar el ocio juvenil. El cuerpo pertenecía al Estado, a la patria, con el objetivo de conseguir unos jóvenes fuertes y sanos que pudieran sostener con sus torsos musculosos el peso del Estado fascista y su expansión política.

Con este artículo también se ha pretendido que todo lo que parecía superfluo dejara de serlo, subrayándose la importancia de los gestos, de los movimientos; llamando atención sobre el significado de los cuerpos, de las prácticas físicas cotidianas, permitiendo que lo que parecía obvio se vuelva analizable. La intención era redescubrir lo distinto, lo original, tornándose la condición corporal como objeto de reflexión y análisis porque, como ya indicó Vigarello (2005, p. 10), "la historia del cuerpo acaba de comenzar".

\section{Referencias}

Bosworth, R. y Dogliani, P. (2001). Italian Fascism: History, Memory and Representation. Basingstoke: Palgrave.

Certeau, M. De (1999). La invención de lo cotidiano. Méjico: Universidad Iberoamericana.

Courtine, J-J. (2005). “Introducción" en Corbin, Alain, Courtine, Jean-Jacques y Vigarello, Georges (coords.): Historia del cuerpo. El siglo XX. Las mutaciones de la mirada, Madrid, Taurus, vol. III.

Elias, N. (1987). El proceso de la civilización. México: Fondo de Cultura Económica.

Falasca-Zamponi, S. (1997). Fascist Spectacle. Los Angeles: University of California Press.

Heller, A y Feher F. (1995). Biopolítica: la modernidad y la liberación del cuerpo. Barcelona, Ed. Península.
Hitler, A. (1995). Mi lucha. Barcelona: Ed. Wotan.

Malvano, L. (1996). "El mito de la juventud a través de la imagen: el fascismo italiano", Levi, Giovanni y Schmitt, Jean-Claude: Historia de los jóvenes. La Edad Contemporánea, Madrid, Taurus, pp. 313-346.

Malvano, L. (2002). "L’immagine di massa: il culto del Duce" en Malvano, Laura: Fascismo e politica dell' immagine, Piamonte, Bollati Boringhieri.

Mnn, E. (1938). Die Erziehung der Jugend im Dritten Reich. Amsterdam.

Martin, S. (2004). Football and Fascism. The national game under Mussolini, Oxford, Berg. 
Michaud, E. (1996). "Soldados de una idea. Los jóvenes bajo el Tercer Reich", Levi, Giovanni y Schmitt, Jean-Claude: Historia de los jóvenes. La Edad Contemporánea, Madrid, Taurus, pp. 349-375.

Mones, J. (1976). "Fascismo y educación", Cuadernos de Pedagogía, suplemento $\mathrm{n}^{\circ} 3$, Barcelona.

Roche, D. (1996). "La cultura material a través de la historia de la indumentaria", Historiografía francesa. Corrientes temáticas y metodologías recientes, Méjico, Universidad Iberoamericana, pp. 77- 88.

Scharagrisky, P. (1998). "Algunas reflexiones sobre el cuerpo durante el franquismo", Educación Física y Ciencia, no 4, pp. 20-49.

Schoenbaum, D. (1967). Hitler's Social Revolution. Class and status in nazi Germany 1933-1939, Londres, Doubleday.

Vigarello, G. (2005). Corregir el cuerpo. Historia de un poder pedagógico, Buenos Aires, Nueva Visión. 